\title{
A EMPREGABILIDADE NOS PARAMMETROS CURRICULARES NACIONAIS: IMPLICAÇÕES E LIMITES A FORMAÇÃO HUMANA
}

\section{Luciano Accioly Lemos Moreira}

\section{RESUMO}

O presente trabalho analisa, à luz da ontologia marxiana, a formação voltada para a empregabilidade contida nos Parâmetros Curriculares Nacionais (1998/1999), nos Temas Transversais (1998) e nas Diretrizes Curriculares Nacionais do Ensino Médio (1999). A análise desta problemática, com base nos fundamentos da perspectiva ontológico-marxiana, permitiu constatar que a formação na perspectiva da empregabilidade articula-se com as categorias da cidadania e do consumidor. A empregabilidade cumpre o papel de adequação dos indivíduos a um mercado de trabalho cada vez mais instável e em crise estrutural, tendo o campo da cidadania e do mercado consumidor como lugares naturais nas disputas e conquistas dos sujeitos sociais. A abordagem defendida pelos Parâmetros Curriculares Nacionais apresenta a sociabilidade do capital como algo insuperável e intocável, cabendo apenas transformar a consciência dos homens, capacitando-os para o enfretamento dos desafios de um mundo tecnologicamente desenvolvido e economicamente mundializado. A critica realizada por nossa análise, pauta-se na explicitação das implicações e limites dessa proposta para a formação humana, compreendendo que a proposta dos documentos analisados mantém os efeitos do trabalho alienado sobre o trabalhador, legitimando e naturalizando a desumanização inerente às relações sociais da sociabilidade capitalista. Quanto à vida coletiva, os Parâmetros Curriculares Nacionais e os Temas Transversais sugerem a cidadania e o mercado consumidor. Entendemos que essa vida coletiva tem uma existência abstrata e vazia de sentido, pois restringe-se ao espaço da política e do mercado, controlados e necessários à reprodução desse sistema. E por fim, tentamos demonstrar as possibilidades de uma atividade educativa que vislumbre uma formação para além do capital.

\section{PALAVRAS-CHAVE}

Empregabilidade; Crise estrutural; Cidadania; Mercado consumidor; Formação humana 


\title{
THE EMPREGABILIDADE IN THE NATIONAL CURRICULAR PARAMETERS: IMPLICATIONS AND LIMITS THE FORMATION HUMAN BEING
}

\begin{abstract}
The present work analyzes, to the light of the marxiana ontologia, the formation directed toward the empregabilidade contained in the National Curricular Parameters (1998/1999), in the Transversal Subjects (1998) and in the National Curricular Lines of direction of Average Ensino (1999). The analysis of this problematic one, on the basis of the beddings of the ontológico-marxiana perspective, allowed to evidence that the formation in the perspective of the empregabilidade is articulated with the categories of the citizenship and the consumer. The empregabilidade fulfills to the paper of adequacy of the individuals to a market of work each unstabler time and in structural crisis, having the field of the citizenship and the consuming market as natural places in the disputes and conquests of the social citizens. The boarding defended for the National Curricular Parameters presents the sociability of insuperável and untouchable the capital as something, fitting only to transform the conscience of the men, enabling them to the enfretamento of the challenges of a world tecnologicamente developed and economically mundializado. It criticizes it carried through for our analysis, guideline in the explicitação of the implications and limits of this proposal for the formation human being, understanding that the proposal of analyzed documents keeps the effect of the mentally ill work on the worker, legitimizing and naturalizing the inherent desumanização to the social relations of the capitalist sociability. How much to the collective life, the National Curricular Parameters and the Transversal Subjects suggest the citizenship and the consuming market. We understand that this collective life has an abstract and empty existence of direction, therefore restricts it the space of the politics and the market, controlled and necessary to the reproduction of this system. E finally, we try to demonstrate the possibilities of an educative activity that has glimpsed a formation for beyond the capital.
\end{abstract}

\section{KEYWORDS}

Empregabilidade; Structural crisis; Citizenship; Consuming market; Formation human being 


\section{ARTIGO Área Temática: Planejamento Educacional}

\section{INTRODUÇÃO}

A formação escolar para a empregabilidade defendida pelos Parâmetros Curriculares Nacionais (1998/1999), Temas Transversais (1998) e as Diretrizes Curriculares Nacionais do Ensino Médio (1999), constitui o objeto de nossa análise. Esse corpo legal, instituído pelo Estado brasileiro na década de 90 do século XX, advoga a idéia de que é necessário alterar a estrutura formativa educacional do Brasil, com o objetivo de situar esse país na economia mundializada e tecnologicamente avançada da contemporaneidade.

Diante da complexidade do tema, fez-se necessário analisar a formação para a empregabilidade tentando capturar a relação entre a educação e a totalidade social. Para isso, compreendemos de maneira dialética o movimento da educação, percebendo essa atividade nem de forma mecânica, reduzindo essa esfera social a uma condição de joguete dos imperativos da economia; nem tampouco, como uma panacéia resolutiva de todos os males sociais que afligem a humanidade. Partiremos da compreensão da educação como uma mediação entre o indivíduo e a sociedade, em que, a partir de sua especificidade, permite ao indivíduo apropriar-se do patrimônio cultural, científico e estético da humanidade, capacitando-os com os conhecimentos necessários e imprescindíveis a sua reprodução como gênero humano.

Dessa maneira, nossa análise realizou um diálogo entre alguns autores da área de trabalho e educação, a fim de captar a origem histórica da formação escolar para a empregabilidade. A categoria da empregabilidade representa o objeto central de nossa pesquisa. O proposto diálogo histórico dessa categoria ajudará na explicitação da nossa problemática, apontando as causas e os efeitos dessa formação.

\section{FORMAÇÃO ESCOLAR E EMPREGABILIDADE: QUE HOMENS QUEREMOS FORMAR?}

A formação escolar, na segunda metade do século XIX, tanto por parte da classe dominante, como da classe trabalhadora, representava a possibilidade de integração social na construção da cidadania dos educandos. A democratização da educação se fazia necessária, já que era imprescindível a formação de um homem para um mundo em processo de industrialização, no qual os direitos burgueses advindos de sua revolução contra o feudalismo, instituíam novos valores e conhecimentos para todas as classes sociais.

De acordo com Gentili (2000), a função da educação apontava para uma possibilidade de integração social entre os indivíduos. Tomar conhecimento dos direitos civis, 


\section{ARTIGO Área Temática: Planejamento Educacional}

políticos e sociais postos pela realidade capitalista, transformava-se no maior objetivo dentre as classes.

Em 1949, T.H. Marshall identifica um outro aspecto em relação à função da educação. Num de seus ensaios, o referido autor defende que "a natureza integradora da escola” (GENTILI, 2000, p.79) se encontraria na dimensão econômica. A percepção de que a educação poderia integrar os indivíduos e a sociedade à produção do capital, no intuito de ampliar a riqueza social de uma nação, possibilitou o surgimento da teoria do capital humano. Essa teoria encontrou um campo fértil, tanto econômico como político. Vivia-se, no período entre 50 e 70 do século XX, o chamado período de ouro do capitalismo. A economia fundada na organização taylorista/fordista mostrava-se como ilimitada em seu poder de acumulação e expansão da riqueza material do capital.

Na política, o Estado de Bem-estar Social garantia o pleno emprego à maioria dos indivíduos. O capital de Keynes abria um panorama de abundância para muitos, poderia-se sonhar com a estabilidade em um posto de trabalho e uma aposentadoria segura e feliz.

Diante dessa realidade de progresso vivido pelo capital entre 1950 a 1970, “a prosperidade material pareceu atingir um nível quase milagroso e uma extensão aparentemente ilimitada. O PIB mundial chegou a crescer a uma média anual de 4,9\%[...]”, ocorrendo uma "expansão do comércio internacional marcada por uma surpreendente variação no volume de exportações de mercadorias que atingiu um crescimento médio anual de 7\%” (GENTILI, 2000, p.82). O capital, nesse momento, intensificava sua mundialização, sua economia alcançava os mais longínquos lugares e espaços do planeta.

Marx, em 1848, já percebia em seus escritos, a determinação expansiva do capitalismo em busca de um mercado mundializado. "A burguesia não pode existir sem revolucionar permanentemente os instrumentos de produção - por conseguinte, as relações de produção e, com isso, todas as relações sociais” (MARX, 1998, p.8). O projeto da modernidade no qual a prosperidade e o desenvolvimento capitalista constituíam-se no fim maior parecia estar em processo de alcançar o seu ápice.

A educação, nesse ínterim, torna-se um lugar integrador entre as potencialidades econômicas dos indivíduos e o desenvolvimento econômico de um país, pois segundo Gentili:

O processo da escolaridade era interpretado como um elemento fundamental na formação do capital humano necessário para garantir a capacidade competitiva das economias e, consequentemente, o incremento progressivo da riqueza social e da renda individual. (GENTILI, 2002, p. 50). 


\section{ARTIGO Área Temática: Planejamento Educacional}

O desenvolvimento econômico e a garantia de pleno emprego abriam à possibilidade concreta de uma ideologia desenvolvimentista. Consequentemente, a qualificação por meio da formação escolar para o trabalhador, ampliaria os lucros do capital e a renda dos trabalhadores. A riqueza dos indivíduos era também a riqueza de uma nação. "Uma sociedade rica deveria ser, necessariamente, uma sociedade de pessoas ricas, assim como uma sociedade competitiva deveria ser, indefectivelmente, uma sociedade de pessoas competitivas" (GENTILI, 2002, p.50).

O Estado, ao assumir o papel de agente principal na democratização da escola para os trabalhadores desse período, deveria planejar as ações, captar recursos e distribuir verbas para a propagação desse sistema escolar ao maior número de trabalhadores, pois os países desenvolvidos poderiam aumentar suas riquezas, enquanto que o terceiro mundo investiria no capital humano na perspectiva do ideal desenvolvimentista de suas economias, alimentando a esperança de equiparar-se economicamente aos países avançados.

Percebe-se que, na conjuntura do pós II Guerra Mundial até 1970, o capital em expansão poderia, independentemente do nível de qualificação do trabalhador, oferecer postos de emprego aos indivíduos. Com isso, a teoria do capital humano se justificava teórica e ideologicamente a partir da possibilidade concreta do capital em oferecer pleno emprego. Maciel reforça essa concepção ao elucidar que:

\footnotetext{
Nessas circunstâncias, a certificação formal desempenhava importante função na alocação e hierarquização do trabalho nas empresas e no mercado como um todo. A qualificação formal servia assim menos como via de acesso ao mercado - até porque a produção em larga escala para o consumidor de massa operava com um grande contigente de trabalhadores(as) desqualificados(as) - e mais, como fator classificatório na hierarquia dos postos de trabalho. A geração de novos postos de trabalho devia-se, isto sim, ao próprio modelo de acumulação e jamais ao grau de qualificação formal dos(as) trabalhadores(as). (MACIEL, 2003, p. 292).
}

Torna-se evidente que a economia possibilitava, nesse período histórico, a expansão dos postos de trabalho, como também, uma maior ascensão da renda do trabalhador com sua produção de massa voltada para um consumo em larga escala.

De qualquer modo, a educação, com sua especificidade e função assumida na sociabilidade do capital, cumpre um importante papel, visto que “é obvio, entretanto, que uma boa certificação fazia diferença na hora do(a) trabalhador(a) assumir seu posto no mercado de trabalho, na competição com os(as) demais” (MACIEL, 2003, p.292). O poder integrador da escola em relação à economia tinha o seu aspecto de qualificar a maioria dos trabalhadores, na perspectiva de mais educação, maior lucro. 


\section{ARTIGO Área Temática: Planejamento Educacional}

Em 1973, com o início da crise estrutural do capital, a proposta integradora econômica da educação também entra em crise, pois adentramos num período em que o capital não conseguia manter os níveis de expansão e acumulação proporcionadores dos postos de empregos antes vivido na era de ouro do capitalismo. Gentili explica que:

[...] a ruptura da promessa da escola como entidade integradora começou a se desencadear de forma definida nos anos de 1980, justamente num contexto de revalorização do papel econômico de educação, da proliferação de discursos que começaram a enfatizar a importância produtiva dos conhecimentos (inclusive a configuração de uma verdadeira "Sociedade do Conhecimento" na Terceira Revolução Industrial) e de uma crescente ênfase oficial nos aportes supostamente fundamentais que as instituições escolares deviam realizar para a competitividade das economias na era da globalização. (GENTILI, 2002, p. 48).

A teoria do capital humano, nos tempos de pleno emprego, com sua equação mais educação $=$ qualificação $=$ garantia de emprego $=$ desenvolvimento social, não tinha $o$ correspondente material expansivo do capital que o justificasse. A refração da economia exigia uma outra construção teórico-ideológica, na qual se fundamenta a estruturação de uma nova formação escolar para uma época de crise do capitalismo.

Sobre essa questão, Gentili afirma que:

estando morta definitivamente a promessa do pleno emprego, restará ao indivíduo (e não ao Estado, às instâncias de planejamento ou às empresas) definir suas próprias opções, suas escolhas que permitam (ou não) conquistar uma posição mais competitiva no mercado de trabalho. A desintegração da promessa integradora deixará lugar à difusão de uma nova promessa, agora sim, de caráter estritamente privado: a promessa da empregabilidade. (GENTILI, 2002, p. 51).

Gentili deixa claro que a noção de empregabilidade não supera os pressupostos básicos da teoria do capital humano. A justificativa ideológica de que a partir de uma maior qualificação ter-se-ia um maior lucro para o capital é preservada nessa nova categoria da empregabilidade. $\mathrm{O}$ que antes se configurava num desenvolvimento que poderia abarcar a grande maioria dos trabalhadores, a partir do momento em que o capital atravessa problemas em seu movimento de auto-reprodução torna o pleno emprego algo impossível de se garantir. A escola passa a ser uma instância de integração dos indivíduos ao mercado, porém, dada a competitividade natural dessa esfera, não haverá a possibilidade de todos participarem. Com isso, apenas os mais capazes sobreviverão. O discurso da integração dá lugar à exacerbação do individualismo burguês e da competição desumanizadora do mercado.

Nos anos 60/70 do séc. 20, tanto os empregados especializados como os não qualificados tinham um lugar ao sol. O emprego alcançava muitos trabalhadores disponíveis, 


\section{ARTIGO Área Temática: Planejamento Educacional}

nunca a totalidade, pois o capital sempre necessita de um exército de reserva para explorar com uma maior intensidade o trabalho. Porém, com a crise estrutural, surge a formação para o mundo do desemprego, voltada para o desenvolvimento de habilidades e competências necessárias ao capital em crise estrutural. Essa noção de formação engloba muito mais do que a antiga formação técnica e formal do taylorismo/fordismo, à qual o trabalhador estava acostumado. "Começa-se a buscar nas virtudes individuais e na qualificação as razões pelas quais alguns conseguem e outros não conseguem empregar-se” (PAIVA, 2002, p.59).

Paralelo ao termo empregabilidade, a noção de competência assume também um lugar de destaque nessa qualificação. Dessa maneira, enquanto a empregabilidade está voltada para a preparação de valores, conhecimentos e virtudes nos indivíduos para a incerteza do emprego, as competências, irão possibilitar aos indivíduos, o surgimento de capacidades subjetivas, flexíveis e criativas para o mundo da concorrência cada vez mais acirrada do mercado de trabalho.

Adaptar-se é a nova palavra de ordem do mercado. A empregabilidade desloca o problema e a solução da possibilidade de emprego para o indivíduo e sua formação. Com isso, a teoria do capital humano é re-significada e adequada aos novos tempos. De acordo com essa ótica, é imprescindível que o trabalhador seja qualificado, porém a responsabilidade passa a ser do empregado, pois a livre concorrência do mercado e a competição farão com que apenas os mais competentes se tornem empregáveis. Valorizam-se, assim, as políticas meritocráticas, em que cada indivíduo deve conquistar por si mesmo uma atividade no mercado.

No Brasil, a partir da década de 90, a empregabilidade e a cidadania configuram-se como os objetivos na formação dos indivíduos. O exercício de direitos e deveres e a capacitação profissional para o mercado de trabalho, em constante transformação tecnológica e organizacional, tornaram-se a meta das políticas educacionais desse período. De acordo com essas políticas:

A internacionalização da economia confronta o Brasil com a necessidade indispensável de dispor de profissionais qualificados. Quanto mais o Brasil consolida as instituições políticas democráticas, fortalece os direitos da cidadania e participa da economia mundializada, mais se amplia o reconhecimento da importância da educação para a promoção do desenvolvimento sustentável e para a superação das desigualdades sociais. (BRASIL, MEC, 2001, p. 3).

As transformações no mercado mundial, no mundo do trabalho e no cotidiano de cada indivíduo são percebidas, por tais políticas, como um processo inerente ao progresso humano. Mesmo que elas tragam a "exclusão", a pobreza e a miséria social, por outro lado, trazem a tecnologia, o progresso e o desenvolvimento. Cabe à educação apreender as dificuldades 


\section{ARTIGO Área Temática: Planejamento Educacional}

como estímulos para o aprendizado escolar, ou seja, as dificuldades devem ser superadas ou mesmo amenizadas por uma melhor qualificação do indivíduo, para um mercado cada vez mais exigente e tecnologicamente moderno. É preciso que os professores "sejam desafiados por situações-problema que os confrontem com diferentes obstáculos, exigindo superação e que experienciem situações didáticas nas quais possam refletir, experimentar e ousar agir, a partir dos conhecimentos que possuem”"1 (BRASIL, 2001, p. 7).

Os Parâmetros Curriculares Nacionais do Ensino Fundamental (PCN) corroboram com essa compreensão, ao afirmar que

O aumento do desemprego e as mudanças no mundo do trabalho é outro aspecto que aflige a sociedade brasileira que demonstra preocupação com o grande contigente de jovens que, mesmo com alguma escolarização, estão mal preparados para compreender o mundo em que vivem e nele atuar de maneira crítica, responsável e transformadora, e, especialmente para serem absorvidos por um mercado de trabalho instável, impreciso e cada vez mais exigente. (PCN, 1998, p.21).

Estar mal ou bem preparado para o mercado de trabalho, conforme as políticas do Estado brasileiro, torna-se o fator determinante de estar ou não empregável. Assim, a realidade social, constituída pela forma como os homens se organizam no e pelo trabalho para a produção de suas vidas, é compreendida por essa política como uma força imutável. O mercado personaliza-se de tal forma que em determinado momento pode comportar-se de forma exigente, instável e impreciso; e amanhã, poderá mudar sua “vontade” em relação ao homem, impondo uma nova formação, a qual corresponda à exigência e necessidade do capital. O homem, para a reprodução dessa forma de sociabilidade, deve ser subsumido ao mercado de modo que sua vida e sua formação passem a ser colocadas em favor dessa força estranha e avassaladora.

Participar no mercado de trabalho e ser cidadão convertem-se no principal objetivo da educação nos dias atuais. As Diretrizes Curriculares para a Formação de Professores ${ }^{2}$ reforçam a concepção da escola "voltada para a construção de uma cidadania consciente e ativa, que ofereça aos alunos as bases culturais que lhes permitam identificar e posicionar-se frente às transformações em curso e incorporar-se na vida produtiva e sócio-política” (BRASIL, MEC, 2001, p. 8).

\footnotetext{
${ }^{1}$ Diretrizes Curriculares Nacionais para a formação de Professores da Educação Básica, em nível superior, aprovado em 2001 pelo o Conselho Nacional de Educação

2 BRASIL. Diretrizes Curriculares Nacionais para a formação de Professores da Educação Básica, em nível superior, aprovado em 2001 pelo o Conselho Nacional de Educação (2001, p.27).
} 


\section{ARTIGO Área Temática: Planejamento Educacional}

Adaptar-se às exigências do mundo "globalizado" sob a égide do capital parece ser a única saída para os países desenvolvidos e em desenvolvimento. A educação, partindo desse pressuposto, tem uma função importante de adaptação e preparação dos educandos e educadores ao mundo globalizado. "Diante desse mundo globalizado, que apresenta múltiplos desafios para o homem, a educação surge como uma utopia necessária indispensável à humanidade na sua construção da paz, da liberdade e da justiça social” (BRASIL, MEC/SEF, 1999, p.30).

Preparar, qualificar e habilitar os educandos com as devidas competências de que o mercado moderno hoje necessita convertem-se em um dos principais objetivos da formação educacional do Brasil.

Os trabalhadores, conforme tais políticas, são os responsáveis por investirem em seu capital humano, tornando-se empreendedores e construtores de suas próprias vidas. Portanto, a empregabilidade almeja desenvolver a competência necessária para armar os indivíduos na disputa por trabalhos tradicionais ainda existentes e potencializar a capacidade criativa e autônoma dos trabalhadores em inventarem formas diferentes de ganharem suas vidas, explorando setores de bens e serviços ainda não explorados pelo capital.

De acordo com os PCN, os sujeitos sociais de nossa época são representados pelos cidadãos e consumidores. A formação para a empregabilidade manteria uma articulação necessária e imprescindível com a cidadania, visto que a luta social se configuraria na união entre o Estado, organizações não-governamentais, a família e os indivíduos em geral, na luta pela amenização dos obstáculos ao desenvolvimento do Brasil.

Os educandos devem, no momento, conhecer seus direitos e deveres, e de maneira consciente, atuar no campo político regido pelo Estado capitalista. Da mesma forma, os trabalhadores-cidadãos devem constituir-se em consumidores conscientes, agindo para a construção de relações equilibradas no mercado consumidor. O consumidor poderá por seu poder de compra, humanizar, equilibrar e harmonizar os excessos desse sistema produtivo. Fecha-se o ciclo por intermédio dessa formação para a empregabilidade. O indivíduo é responsável, isoladamente, por sua empregabilidade; e como cidadão, poderá participar do espaço político cedido pelo capital a uma vida coletiva conservadora da propriedade privada, do trabalho alienado e do estado burguês; e por último, o trabalhador-cidadão poderá conquistar a condição de consumidor ativo, atuando no campo restrito do mercado capitalista. 


\section{ARTIGO Área Temática: Planejamento Educacional}

\section{CONCLUSÃO}

A empregabilidade se apresenta como um projeto ideológico formador em resposta a crise estrutural do capital contemporâneo. Na história do capitalismo, a sujeição da classe trabalhadora à exploração do capital oscilou pelo uso da força, da expropriação legal e violenta, da instauração de leis contra a vagabundagem, das políticas públicas assistencialistas aos desempregados; enfim, o capital junto com o Estado precisou e precisa resignificar seus instrumentos de controle a cada momento histórico. A educação formal sistematizada e controlada pelo estado se constitui num espaço importante na formação dos saberes culturais dos indivíduos. E nesse momento, precisa, como resposta a um desemprego crônico inerente a crise que se abate na estrutura do sistema do capital em 1970, interpelar os homens a essa realidade, induzindo-os, motivando-os e capacitando-os a agirem e atuarem no campo minado da instabilidade de um mundo do desemprego, do emprego precário e do subemprego.

Por mais que essa formação traga avanços curriculares introduzindo temas e problemas atuais e necessários a nossa época, não apreendem e nem ultrapassam os males sociais, econômicos e políticos inerentes ao capitalismo em crise estrutural.

Dessa maneira, contrariando radicalmente a compreensão dos PCN, entendemos que as relações do capital, fundada pela lógica antagônica de uma classe dominante sobre outra, fazem a educação sofrer em sua essência um rebaixamento de sua função, já que se o homem em sua vida real é alienado de seu mundo material e espiritual, a formação escolar também é perpassada por esses antagonismos e limites.

O desenvolvimento do homem no sistema do capital não pode ser realizado em sua plenitude, visto que grande parte da população é impedida de apropriar-se da riqueza produzida pelo gênero humano. A formação escolar, que cumpre uma parte importante na conservação e transmissão da cultura produzida pelos homens, é limitada pela vida estreita em que os homens produzem e reproduzem suas vidas no capital.

O caráter social da produção e reprodução da vida dos homens pelo trabalho e pelas esferas sociais que medeiam suas relações é alienado a um poder misterioso. O capital se coloca como o fim, e o trabalho abstrato (produtor de mais-valia), um meio de realização da riqueza privada capitalista.

Porém, a sociedade regida pelo capital é contraditória e não homogênea. A hegemonia e o controle econômico, político, social, ideológico e cultural do capital sobre as relações sociais não se desenvolvem de forma unilateral e sem saída. Há, no próprio antagonismo de 


\section{ARTIGO Área Temática: Planejamento Educacional}

classe, a possibilidade concreta de um ponto de vista radicalmente contrário e superior no que diz respeito à superação positiva dessa alienação.

Entendemos que a educação pode contribuir no enfrentamento de uma formação para a empregabilidade, ou seja, na continuidade e aprofundamento da exploração do homem pelo homem. Porém, sabemos que a possibilidade de atividades educativas que tenham como norte a superação do capital não confere a educação um status de centralidade desse processo. É no trabalho, vale reafirmar, que se encontra o lugar ontológico dessa empreitada revolucionária, porém, a educação, partindo do ponto de vista da emancipação humana, poderá contribuir na construção de uma ordem social além do capital.

As atividades educativas direcionadas na contramão da ordem do capital serão sempre nessa forma de sociabilidade, representadas por ações formativas parciais, restritas e isoladas. Não podendo, com isso, se transformar num sistema integrado, normativo e universalmente praticado como oposição real à educação dominante. A educação dominante que visa à conservação do capital detém, nessa sociabilidade, uma hegemonia (não homogênea) sistemática da formação escolar. Um sistema educativo que vise à autoconstrução do homem será apenas universalizante e concretamente existente, em todo o seu potencial libertador, numa sociabilidade comunista.

\section{REFEÊNCIAS}

AZEVEDO, J. C.; GENTILI, P.; KRUG, A.; SIMON, C. (Org.). Utopia e democracia na educação cidadã. Porto Alegre: Ed. Universidade/UFRGS/ Secretaria Municipal de Educação, 2000.

BRASIL, "Lei n 9.394, de 20.12.96, Estabelece as diretrizes e bases da educação nacional”, 1996.

BRASIL, Referenciais para a Formação de Professores / Secretaria de Educação Fundamental. Brasília, 1999.

BRASIL, MEC, Parecer $n^{\circ}$ 009/2001, Diretrizes Curriculares Nacionais para a formação de professores da educação básica, em nível superior, curso de licenciatura, de graduação plena. Brasília, 2001.

BRASIL, MEC/SEF. Parâmetros Curriculares Nacionais: História e Geografia. Brasília, 1997.

Parâmetros Curriculares Nacionais do Ensino Fundamental. Brasília, 1998. 
Parâmetros Curriculares Nacionais do Ensino Médio. Brasília, 1999.

CHESNAIS, F. A mundialização do capital. São Paulo: Xamã, 1996.

FIGUEIREDO, F. F.; MENEZES, A. M. D. (Org.). Trabalho, sociabilidade e educação: uma crítica à ordem do capital. Fortaleza: Editora UFC, 2003.

FRIGOTTO, G.; GENTILI, P. (Org.). A cidadania negada: políticas de exclusão na educação e no trabalho. São Paulo: Cortez, 2002.

GENTILI, P. (Org.). Pedagogia da exclusão: crítica ao neoliberalismo em educação. 7. ed. Petrópolis: Vozes, 2000. 